\title{
PCR-RFLP markers identify three lineages of the North American and European populations of Phytophthora ramorum
}

\author{
By M. Elliott ${ }^{1}$, G. Sumampong ${ }^{2}$, A. Varga ${ }^{3}$, S. F. Shamoun ${ }^{2,6}$, D. James ${ }^{3}$, S. Masri ${ }^{3}$, \\ S. C. Brière ${ }^{4}$ and N. J. Grünwald ${ }^{5}$ \\ ${ }^{1}$ Puyallup Research and Extension Center, Washington State University, Puyallup, WA 98371, USA; \\ ${ }^{2}$ Canadian Forest Service, Pacific Forestry Centre, Victoria, BC, Canada; ${ }^{3}$ Sidney Laboratory, \\ Canadian Food Inspection Agency, Sidney, BC, Canada; ${ }^{4}$ Ontario Plant Laboratories, \\ Phytopathology Laboratory, Canadian Food Inspection Agency, Ottawa, ON, Canada; \\ ${ }^{5}$ Horticultural Crops Research Laboratory, USDA ARS, Corvallis, OR, USA; \\ ${ }^{6}$ E-mail: sshamoun@pfc.cfs.nrcan.gc.ca (for correspondence)
}

\begin{abstract}
Summary
Phytophthora ramorum, the cause of sudden oak death and ramorum blight, has three major clonal lineages and two mating types. Molecular tests currently available for detecting $P$. ramorum do not distinguish between clonal lineages and mating type is determined by cultural methods on a limited number of samples. In some molecular diagnostic tests, cross-reaction with other closely related species such as $P$. hibernalis, $P$. foliorum or $P$. lateralis can occur. Regions in the mitochondrial gene Cox1 are different among $P$. ramorum lineages and mitochondrial genotyping of the North American and European populations seems to be sufficient to differentiate between mating types, because the EU1 lineage is mostly A1 and both NA1 and NA2 lineages are A2. In our study, we were able to identify $P$. ramorum isolates according to lineage using polymerase chain reaction-restriction fragment-length polymorphism (PCR-RFLP) of the Coxi gene, first by using ApoI to separate $P$. ramorum from other species and EU1 from North American populations, and then AvaI to distinguish between NA1 and NA2 genotypes. However, $P$. foliorum had the same restriction profile as $P$. ramorum NA1 isolates.
\end{abstract}

\section{Introduction}

Phytophthora ramorum S. Werres \& A.W.A.M. de Cock (Oomycetes: Peronosporales), the cause of sudden oak death in the US and ramorum blight in Europe, causes damage on more than 70 species of trees and shrubs (USDA-APHIS 2007). Nursery stock is one of the primary modes of transmission and countries where the disease is found have quarantine measures to prevent further spread (EPPO 2006). The disease has been detected and eradicated several times from nurseries in British Columbia between the years 2003 and the present. Early detection and eradication in nurseries are critical to keeping $P$. ramorum out of the forest environment (MASCHERETTI et al. 2008). As the organism is microscopic and symptoms resemble those of other plant pathogens or are innocuous on some hosts, detection is problematic. Based on molecular data, there are three clonal lineages of $P$. ramorum (Ivors et al. 2006): one from Europe (EU1) and two from North America (NA1 and NA2).

Phytophthora ramorum is heterothallic, requiring two mating types (A1 and A2) for sexual reproduction. A sexually reproducing population of $P$. ramorum could give rise to new genotypes that may be more damaging than the parent strains, and have an increased host range or tolerance for more extreme environmental conditions. There is evidence for 
the occurrence of sexual reproduction in P. ramorum in the past, creating new clonal lineages that proliferate asexually (MASCHERETTI et al. 2008).

Mating type in $P$. ramorum is determined by crossing a given isolate with tester isolates of known mating type and observing the formation of sexual structures. This test is timeconsuming and not always reliable because some isolates will not mate in culture. In addition, only a small number of isolates have been tested for mating type and this test is not done routinely when examining samples from nursery surveys. A molecular diagnostic test based on mating-type genes in $P$. ramorum has not yet been developed, because these genes in Phytophthora are poorly understood and have not yet been cloned or sequenced (Judelson 1996; Gu and Ko 2005). However, mitochondrial genotyping of the North American and European populations seems to be sufficient for differentiating between mating types, because the EU1 population is mostly A1 with a few exceptions (WERRES and De Merlier 2003) and both NA1 and NA2 lineages are A2. Both mating types have the same host range, and pathogenicity to different hosts appears to be similar for a given isolate (BRASIER et al. 2006).

The A1 mating type of P. ramorum is found in Europe and North America, but is the predominant mating type in Europe (Hansen et al. 2003; Prospero et al. 2007). All A1 isolates discovered belong to the EU1 lineage (BRASIER et al. 2006). Isolates of P. ramorum collected from forests in California and Oregon form a separate clade based on mitochondrial DNA sequences and microsatellite data (Ivors et al. 2006; Prospero et al. 2007; MARTIN 2008) and all the isolates tested belong to the A2 mating type. This clonal lineage is designated 'NA1' and includes the genome-sequenced strain, Pr102 (TYLER et al. 2006). However, some isolates from North American nurseries belonging to the A2 mating type behave phenotypically like EU1 isolates, being fast growing and having similar colony morphology. These isolates have a unique mitochondrial and microsatellite genotype and belong to the NA2 clonal lineage (Ivors et al. 2006; MARTin 2008). The NA2 clade is distinctly different from EU1 and NA1, and has so far only been found in North American nurseries. The differences in the A1 and A2 mating types and their the obstacles to mating in culture, as well as the lack of evidence for sexual reproduction in isolates collected to date where both mating types coexist, suggest a mating barrier in P. ramorum (BRAsIER et al. 2005). All three lineages of $P$. ramorum have been found in North American nurseries (Grunwald et al. 2008).

Phytophthora lateralis Tucker \& Milbrath is a closely related species found in the forest environment but does not cross-amplify with $P$. ramorum-specific primers in the mitochondrial Cox1 region (Kroon et al. 2004; Martin et al. 2004). Phytophthora foliorum Donahoo \& Lamour is a species described recently and found on azalea during nursery surveys for P. ramorum (DonAHoo et al. 2006). Phytophthora hibernalis Carne, like $P$. ramorum and $P$. foliorum, is another species found in nurseries (BLOMQUisT et al. 2005; YAKabe et al. 2007). Phytophthora bibernalis is a known pathogen on citrus (Goodwin et al. 1995), and was found in an Oregon nursery during surveys for $P$. ramorum on rhododendron (Osterbauer et al. 2004). Unlike $P$. ramorum, both $P$. foliorum and $P$. hibernalis are homothallic and do not require the presence of an opposite mating type to form sexual structures. Neither $P$. foliorum nor $P$. hibernalis forms chlamydospores. All three of these species belong to clade 8c (BLAIR et al. 2008) and produce deciduous sporangia, making airborne or water-splash dispersal possible. Longterm survival structures are asexual chlamydospores in $P$. ramorum and sexual oospores in P. foliorum and P. hibernalis (Ho and Jong 1993; Werres et al. 2001; Donahoo et al. 2006).

Many polymerase chain reaction (PCR)-based diagnostic tests for P. ramorum use the ribosomal ITS region to differentiate between Phytophthora species but are not sensitive enough to distinguish between closely related Phytophthora species or clonal lineages of P. ramorum (Kroon et al. 2004; Osterbauer et al. 2004; Blomquist et al. 2005; 
Osterbauer and Trippe 2005; Donahoo et al. 2006). The mitochondrial gene Cox1 was chosen for molecular typing in this study because of the presence of regions that are different among $P$. ramorum clonal lineages (KROON et al. 2004; Ivors et al. 2006; MARTIN 2008). The Cox 1 gene is present in high copy numbers in the genome, providing a larger target concentration than single-copy genes.

The objectives of this study were to develop a polymerase chain reaction-restriction fragment-length polymorphism (PCR-RFLP) marker that would distinguish between NA1 and NA2 genotypes of $P$. ramorum and the closely related species $P$. foliorum, $P$. hibernalis and $P$. lateralis.

\section{Materials and methods}

\subsection{Isolates}

A collection of 23 isolates representing the geographic range and all three clonal lineages of P. ramorum were examined. These included five from Europe and 18 from North America. Other closely related Phytophthora species such as $P$. hibernalis, $P$. lateralis and $P$. foliorum were included for comparison (Table 1). Isolates were imported into Canada under permits P-2006-00625, P-2006-00626 and P-2006-00627 issued by the Canadian Food Inspection Agency. The collection of isolates imported from the United States included isolates from the US and Europe and was studied at the Pacific Forestry Centre, Canadian Forest Service, Victoria, BC, while isolates from Canada were studied at the Sidney Laboratory, Canadian Food Inspection Agency, Sidney, BC. All isolates were collected between 1995 and 2005, with most collected in the years 2002-2003.

\subsection{Selection of a restriction enzyme for differentiation of NA1 and NA2 genotypes}

Sequences of the Cox1 gene (Ivors et al. 2006) were downloaded from GenBank and aligned using ClustalX version 1.8 (Thompson et al. 1997). Virtual restriction digests were performed using RestrictionMapper v. 3.0 (http://www.restrictionmapper.org/). Three enzymes (AvaI, Sml1 and Xho1) distinguished between the two North American A2 mitochondrial genotypes (NA1 and NA2) at the 373 position of the $972-b p$ amplicon, and of these the restriction enzyme AvaI was chosen (Fig. 1).

\subsection{DNA extraction}

Pure cultures of $P$. ramorum, $P$. hibernalis, $P$. lateralis and $P$. foliorum (Table 1 ) were grown in the dark for 10 to 14 days at $20^{\circ} \mathrm{C}$ on $20 \%$ V8 juice agar overlaid with cellophane (BioRad, Mississauga, ON, Canada). Mycelia were harvested ( $100 \mathrm{mg}$ fresh weight) and $50-100 \mathrm{mg}$ sand (Sigma-Aldrich, Oakville, ON, Canada) was added to the mycelia in a 1.5-ml Eppendorf tube. Liquid nitrogen was added and the mycelia were ground to a powder using a micropestle. Total DNA was extracted using the Nucleospin kit (Macherey-Nagel, Düren, Germany) according to the manufacturer's instructions for fungi. The DNA pellet was dissolved in $100 \mu \mathrm{l}$ of TE [10 mM Tris- $\mathrm{HCl}, \mathrm{pH} 8.0$ and $1 \mathrm{~mm}$ ethylenediaminetetraacetic acid (EDTA)] provided from the kit, and the solution was stored at $-20^{\circ} \mathrm{C}$.

\subsection{PCR amplification}

For amplification of the Cox1 gene, the CoxF4N 5'-GTATTTCTTCTTTATTAGGTGC-3' and CoxR4N 5'-CGTGAACTAATGTTACATATAC-3' primers were used to amplify a fragment of $972 \mathrm{bp}$ (KROON et al. 2004). The reaction mix consisted of 10 to 20 ng of template DNA, $200 \mu \mathrm{m}$ dNTP (Amersham Biosciences, Montreal, Quebec, Canada), 1 U of Gold Taq 


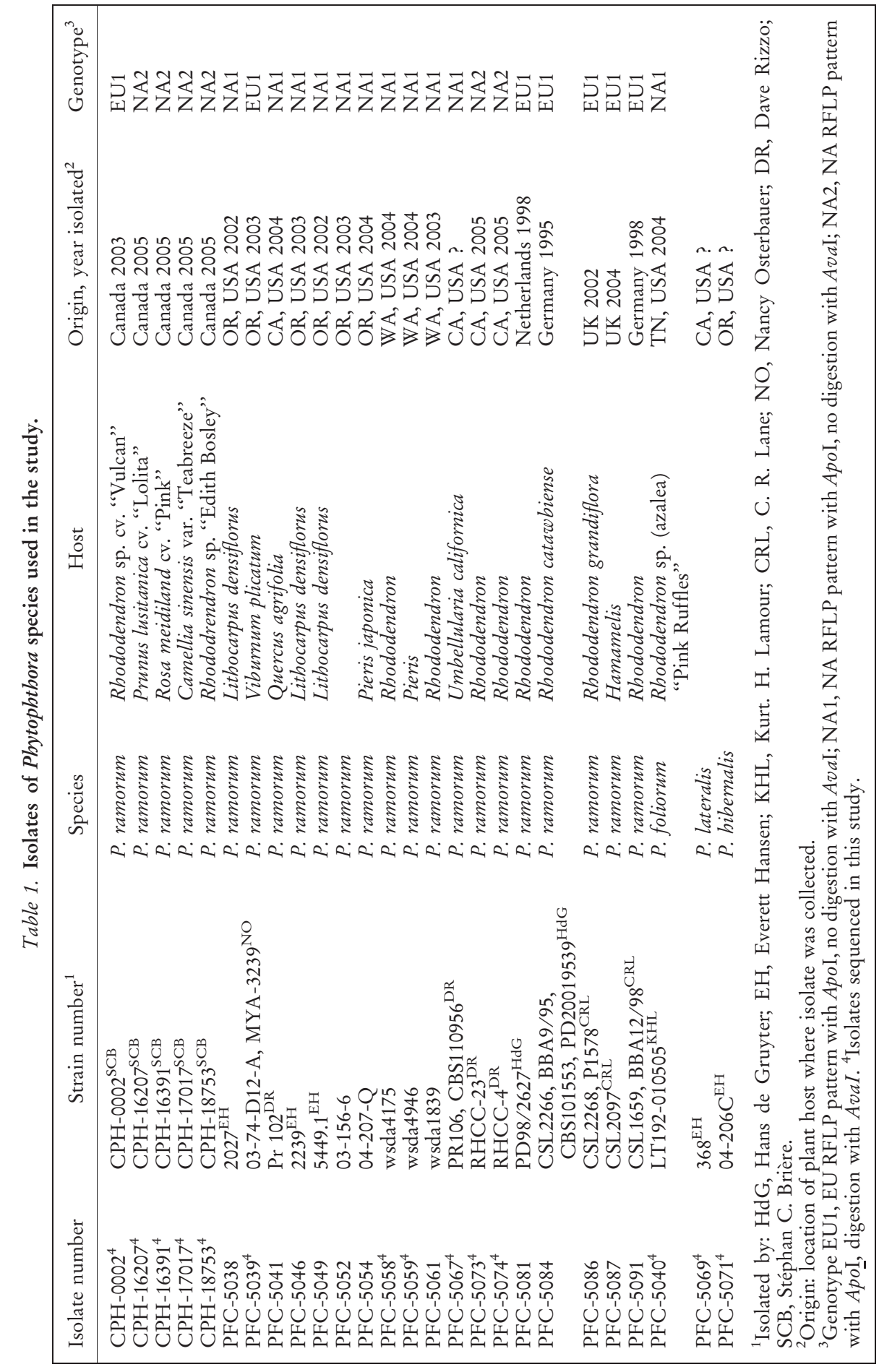




$\begin{array}{ll}\text { DQ117982.1 } & \text { ACTAGAGCTT } \\ \text { DQ117984.1 } & \text { ACTAGAGCTT } \\ \text { DQ117985.1 } & \text { ACTAGAGCTT } \\ \text { DQ117983.1 } & \text { ACTAGAGCTT } \\ \text { DQ117986.1 } & \text { ACTCGAGCTT } \\ \text { AY564183.1 } & \text { ACTCGAGCTT } \\ \text { DQ117981.1 } & \text { ACTCGAGCTT } \\ \text { AY564191.1 } & \text { ACTCGAGCTT }\end{array}$

\author{
Phytophthora ramorum isolate 509 \\ Phytophthora ramorum isolate CBS101553* \\ Phytophthora ramorum isolate Pr102* \\ Phytophthora ramorum isolate Pr218 \\ Phytophthora ramorum isolate PrWA0692 \\ Phytophthora hibernalis isolate CBS 522.77 \\ Phytophthora lateralis isolate PL33 \\ Phytophthora lateralis isolate CBS 168.42
}

Fig. 1. Sequence alignment of bases 370-378 of the 972 bp fragment of the cytochrome C oxidase subunit 1 gene showing the restriction site for AvaI at position 373 (shaded). GenBank accession numbers for each sequence are shown. "Isolates used in the present study.

DNA polymerase (Biocan Scientific Inc., Montreal, Quebec), $3.5 \mathrm{mM} \mathrm{MgCl}_{2}$, 1 X PCR buffer and $25 \mathrm{ng}$ of each primer $(\mathrm{CoxF} 4 \mathrm{~N}$ and CoxR4N) in a reaction volume of $25 \mu \mathrm{l}$. Amplifications were run in an (Applied Biosystems, Foster City, CA, USA) GeneAmp PCR System 9700 thermocycler using conditions described in KroON et al. (2004): an initial denaturation at $94^{\circ} \mathrm{C}$ for $2 \mathrm{~min}$, followed by 35 cycles consisting of denaturation at $94^{\circ} \mathrm{C}$ for $30 \mathrm{~s}$, annealing at $52^{\circ} \mathrm{C}$ for $30 \mathrm{~s}$, and extension at $72^{\circ} \mathrm{C}$ for $60 \mathrm{~s}$. A final extension at $72^{\circ} \mathrm{C}$ for 10 min followed.

A nested PCR primer pair specific for P. ramorum, which amplifies a segment located within the 972-bp fragment amplified by the CoxF4N and CoxR4N primers, was also used (Kroon et al. 2004). Primers Prnest F 5'-TAGCTACTTTATGGGGTGGTTCA-3' (base pairs 508 to 530 of the 972-bp fragment) and PrnestR 5'-CATTCCAACCACTCATAGCATCA-3' (base pairs 869 to 891) amplify a fragment of 383 bp within the Cox1 gene including a single nucleic polymorphism site that distinguishes between EU and NA populations of $P$. ramorum (KROON et al. 2004). The PCR reaction mix and amplification conditions were identical to those for CoxF4N and CoxR4N, except that the annealing temperature was increased to $69^{\circ} \mathrm{C}$.

\subsection{RFLP analysis}

The 972-bp PCR fragment of the Cox1 gene, amplified using the CoxF4N and CoxR4N primer pair, was digested with the restriction enzyme AvaI (C[C/T]CG[A/G]G) (New England Biolabs, Beverley, MA, USA) for $2 \mathrm{~h}$ at $37^{\circ} \mathrm{C}$ according to manufacturer's instructions. The 383-bp PCR fragment of the Cox1 gene, amplified using the Prnest $\mathrm{F}$ and Prnest $\mathrm{R}$ primer pair, was digested with the restriction enzyme ApoI ([A/G]AATT[C/T]) (New England Biolabs) for $2 \mathrm{~h}$ at $50^{\circ} \mathrm{C}$ according to the manufacturer's instructions. The resulting fragments were separated by gel electrophoresis on $2 \%$ and $3 \%$ agarose (BioRad Certified Molecular Biology Agarose, Cat. no. 161-3102) in 1X TBE buffer (Sigma, Cat no. T4415-4L) run at $130 \mathrm{~V}$ for 2 and $2.25 \mathrm{~h}$, respectively. The DNA fragments were visualized after staining with ethidium bromide and illumination under UV light. The image was produced using Syngene's GeneSnap System (Version 6.05.01; Synoptics Ltd, Frederick, MD, USA). Exposure time was 0.44 s. The sharpen tool was used once, which increases fine details (the high spatial frequencies) by adding the difference between the original image and a locally averaged version (Synoptics Ltd).

\subsection{Sequence analysis}

Polymerase chain reaction fragments of representative EU1, NA1 and NA2 (Table 1) were gel-purified and extracted using Qiagen's MiniElute Gel Extraction kit (Qiagen, Mississauga, ON, Canada). Once purified, the addition of $3^{\prime}$-A-overhangs were performed using the TOPO TA cloning kit (Invitrogen, Burlington, ON, Canada) and these PCR 
amplicons were then ligated into the pCR 2.1-TOPO vector using the TOPO TA cloning kit as per the manufacturer's instructions (Invitrogen). Products were sequenced by automated fluorescent DNA cycle sequencing on a LI-COR 4200 DNA Sequencer (LI-COR Biotechnology, Lincoln, NB, USA) at The Centre for Biomedical Research DNA Sequencing Facility at the University of Victoria. The DNA-sequencing kit used was the EPICENTRE (EPICENTRE Biotechnologies, Madison, WI, USA) SequiTherm EXCEL II DNA sequencing kit and the primers (M13F and M13R) were fluorescently labelled.

\subsection{Phylogenetic analyses of partial Cox1 sequence}

Partial Cox1 nucleotide sequences from this study and other accessions of Phytophthora species were aligned using ClustalX, Version 1.83 (Thompson et al. 1997). Default multiple parameters were used to generate the alignment. A phylogenetic tree was generated within ClustalX using the Neighbour Joining method with 1000 bootstrap replicates and visualized using NJPlot (PERrière and Gouy 1996).

\section{Results}

\subsection{PCR amplification}

Using primers CoxF4N and CoxR4N, a 972-bp fragment from the Cox1 gene was amplified from all $23 P$. ramorum isolates and from the $P$. foliorum, $P$. lateralis and $P$. hibernalis isolates. The inner primers PrnestF and PrnestR amplified a 383-bp fragment from all 23 $P$. ramorum isolates mentioned above. The isolate of $P$. bibernalis showed crossamplification using inner primers PrnestF and PrnestR, as did the isolate of $P$. foliorum. The $P$. lateralis isolate did not amplify using inner primers PrnestF and PrnestR.

\subsection{RFLP analysis}

An SNP at position 706 of the 972-bp amplicon (position 199 of the 383-bp amplicon) was found after sequence analysis of the Cox1 fragment that was amplified with DNA from representative EU1, NA1 and NA2 isolates of P. ramorum (Fig. 2). This contributed to a change in the ApoI RFLP profile of this fragment allowing distinction of EU1 from North American (NA1 and NA2) isolates (Fig. 3a,b). One isolate (CPH-0002) from Canada and

\begin{tabular}{|c|c|c|c|}
\hline $\mathrm{CPH} 0002$ & CAN & TTAGATGTAGATACTAGAGCTTATTTTTCTGCAGC.. & ...GAAATTTTAGGTCAAATCCATTTTTGGTTATTTT \\
\hline CPH16207 & CAN & TTAGATGTAGATACTCGAGCTTATTTTTCTGCAGC.. & IAAATTTTAGGTCAAATTCATTTTTGGTTATTCT \\
\hline CPH16391 & CAN & TTAGATGTAGATACTCGAGCTTATTTTTCTGCAGC.. & GAAATTTTAGGTCAAATTCATTTTTGGTTATTCT \\
\hline CPH18753 & CAN & TTAGATGTAGATACTCGAGCTTA--TTTTCTGCAGC. & .. GAAATTTTAGGTCAAATTCATTTTTGGTTATTCT \\
\hline PFC5073 & US & TTAGATGTAGATACTCGAGCTTATTTTTCTGCAGC.. & GAAATTTTAGGTCAAATTCATTTTTGGTTATTCT \\
\hline PFC5074 & US & TTAGATGTAGATACTCGAGCTTATTTTTCTGCAGC.. & GAAATTTTAGGTCAAATTCATTTTTGGTTATTCT \\
\hline PFC5039 & US & TTAGATGTAGATACTAGAGCTTATTTTTCTGCAGC.. & GAAATTTTAGGTCAAATCCATTTTTGGTTATTTT \\
\hline PFC5058 & US & TTAGATGTAGATACTAGAGCTTATTTTTCTGCAGC.. & GAAATTTTAGGTCAAATTCATTTTTGGTTATTTT \\
\hline PFC5059 & US & TTAGATGTAGATACTAGAGCTTATTTTTCTGCAGC.. & GAAATTTTAGGTCAAATTCATTTTTGGTTATTTT \\
\hline PFC5067 & US & TTAGATGTAGATACTAGAGCTTATTTTTCTGCAGC.. & GAAATTTTAGGTCAAATTCATTTTTGGTTATTTT \\
\hline PFC5041-foliorum & US & TTAGATGTAGATACAAGAGCTTATTTTTCAGCAGC. & ..GAAATTTTAGGTCAAATTCATTTTTGGTTATTCT \\
\hline PFC5061-lateralis & US & TTAGATGTAGATACTCGAGCTTATTTTTCTGCAGC.. & ...GAAATTTTGGGTCAAATTCATTTTTGGTTATTCT \\
\hline \multirow[t]{4}{*}{ PFC5071-hibernalis } & US & TTAGATGTAGATACTCGAGCTTATTTTTCTGCAGC.. & ...GAGATTTTAGGCCAAATTCATTTTTGGTTATTCT \\
\hline & & CTCGAG & AAATTC \\
\hline & & AvaI & ApoI \\
\hline & & 393 & 722 \\
\hline
\end{tabular}

Fig. 2. Partial sequence alignment of the 972-bp amplicon (bases 359-722) of the cytochrome C oxidase subunit 1 gene for 10 isolates of Phytophthora ramorum from the United States, Europe and Canada, and one isolate each of $P$. foliorum, $P$. hibernalis and $P$. lateralis. Shaded areas include restriction sites for AvaI at position 373, which distinguishes between NA1 and NA2 genotypes of $P$. ramorum and the ApoI restriction site at position 706 present in NA $P$. ramorum isolates, as well as $P$. foliorum, $P$. hibernalis and $P$. lateralis. Isolate information is listed in Table 1. 
(a)

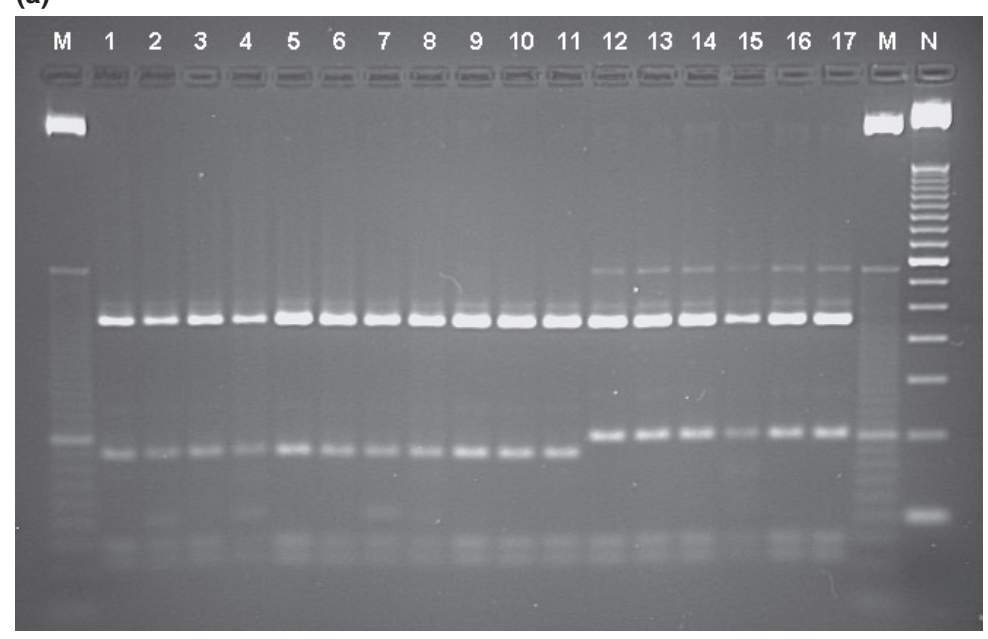

(b)

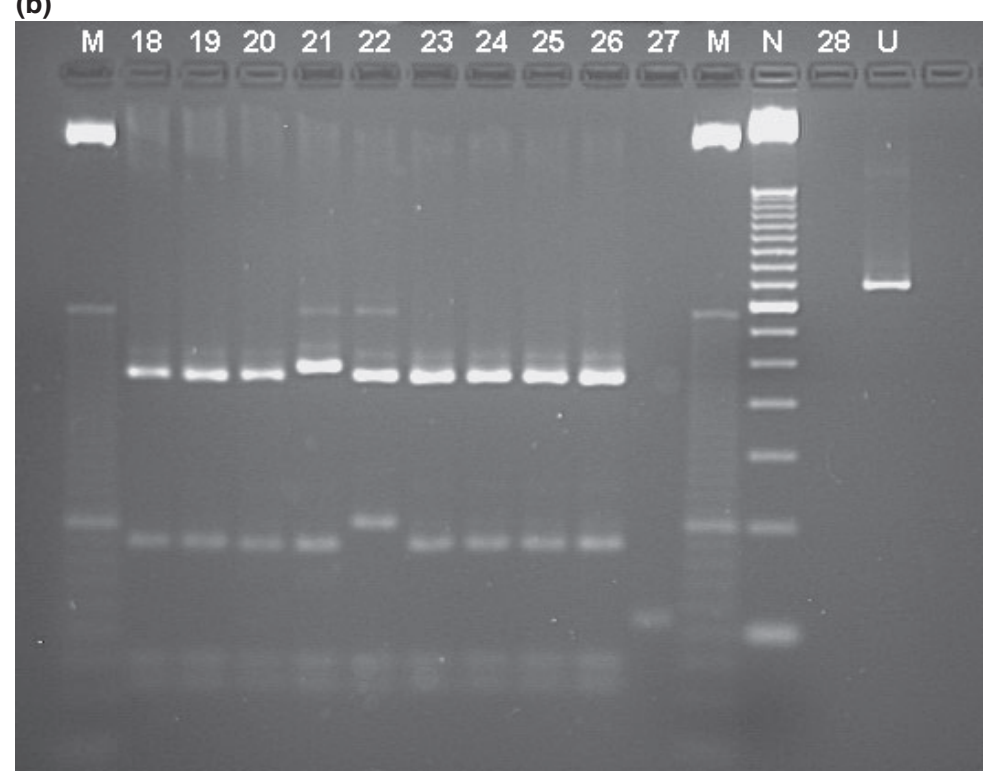

Fig. 3. (a,b) Restriction fragment-length polymorphism patterns for the inner 383-bp amplicon of the cytochrome C oxidase subunit 1 gene for 23 samples of DNA from isolates of Phytophthora ramorum from Europe (lanes 12, 13, 14, 15, 16, 17), the US (lanes 1-11, 18, 19) and Canada (lanes 22, 23, 24, 25, 26), ApoI digests from an isolate of $P$. foliorum (lane 20) and $P$. bibernalis (lane 21). Lane $\mathrm{U}=$ undigested PCR product. Details on isolates are listed in Table 1. A 100-bp (lane M) and 50-bp marker (lane N) is used as size reference. Lane 27 is a no template PCR control. Lane 28 is empty.

one from the US (PFC-5039) have a cytosine residue at position 706, similar to the European isolates reported by Kroon et al. 2004. These isolates are designated 'EU1'. All NA1 and NA2 isolates, as well as $P$. foliorum, $P$. hibernalis and $P$. lateralis have a thymine residue at position 706. 
Using the internal primers PrnestF and PrnestR, the 383-bp Cox1 fragment was amplified only from $P$. ramorum, $P$. foliorum and $P$. hibernalis, but not from $P$. lateralis. In total, four ApoI sites were found throughout the sequences and four distinct RFLP profiles were observed (Fig. 3a,b). EU1 isolates of $P$. ramorum possessed a unique profile, but NA1 and NA2 isolates shared a similar profile with $P$. foliorum. Although cross-amplification for $P$. hibernalis occurred, digestion of the 383-bp amplicons with ApoI generated restriction profiles that could differentiate $P$. hibernalis from $P$. ramorum. Fragment sizes for $P$. hibernalis were 235, 84, 37 and $27 \mathrm{bp}$, compared with 223, 97, 37 and 27 bp for EU1 isolates and 223, 84, 37, 27 and 12 bp for NA1 and NA2 isolates and P. foliorum.

A second SNP was found at position 373 of the 972-bp amplicon that contributed to a change in the AvaI RFLP profile, allowing distinction of NA1 isolates (PFC-5058, PFC5059, PFC-5067) from NA2 isolates (PFC-5073, PFC-5074, CPH-18753, CPH-16207, $\mathrm{CPH}-16391$ ) (Fig. 4a,b). Isolates belonging to the NA1 lineage (PFC-5058, PFC-5059, PFC-5067) have an adenine residue at position 373, which is shared by two EU1 isolates: CPH-0002 from Canada, PFC-5039 from the US, and P. foliorum (PFC-5040). NA2 isolates have a cytosine residue at position 373 (Fig. 2).

The 972-bp Cox1 fragment was amplified from $P$. ramorum, $P$. foliorum, $P$. hibernalis and $P$. lateralis using primers CoxF4N and CoxR4N. Only one AvaI site was found among the sequences and two distinct RFLP profiles were observed (Fig. 4a,b). NA2 isolates of $P$. ramorum, $P$. hibernalis and $P$. lateralis shared the same profile (fragment sizes of 534 and $438 \mathrm{bp})$. The 972-bp Cox1 fragment of the NA1 and EU1 isolates of P. ramorum and $P$. foliorum was not digested by AvaI.

\subsection{Phylogenetic analyses of partial Cox1 sequence}

GenBank accession numbers for isolates sequenced in this study and for sequences obtained from GenBank are shown in Fig. 5. Based on Neighbour Joining analyses of Cox1 sequences from our $P$. ramorum isolates and other accessions, three distinct clades were observed (Fig. 5). Within the NA1 clade, isolates PFC-5058 and PFC-5059 grouped with other similar genotypic representative members. Isolates CPH-16207, CPH-16391 (two sequences 16391-a and 16391-b), CPH-18753, and PFC-5074 grouped together with PrWA0692 (accession DQ117986.1) together forming the NA2 clade. From this study, members of the EU1 clade included PFC-5039 and CPH-0002 and were grouped together with other EU1 Cox1 genotypes. Based solely on the partial Cox1 sequence, PFC-5067 and PFC-5073 did not show a distinct grouping within any clade.

Sequences generated from isolates of $P$. hibernalis and $P$. lateralis from this study grouped with conspecific accessions. $P$. foliorum formed a distinct branch. Other species (P. heveae, $P$. cryptogea, $P$. citricola, $P$. megasperma, $P$. katsurae and $P$. megakary) also formed distinct species groupings.

\section{Discussion}

As more information about $P$. ramorum has accumulated, it has become clear that it is important to identify $P$. ramorum not only to the species level, but also to the clonal lineage and mating type level. In addition to sexual reproduction, new genotypes can arise by horizontal transmission of genes between different asexually reproducing populations of Phytophthora. The mechanisms by which this occurs may include heterokaryosis (Judelson and YANG 1998), viruses (Tooley et al. 1989) or transposable elements (Goodwin et al. 1995; Pritham et al. 2007). Because P. ramorum has two mating types, sexual reproduction can occur only when both mating types are present in the same location. In most cases, these mating types are restricted to different continents. The European lineage (EU1, mostly A1 mating type) has been found consistently in Europe, 
(a)

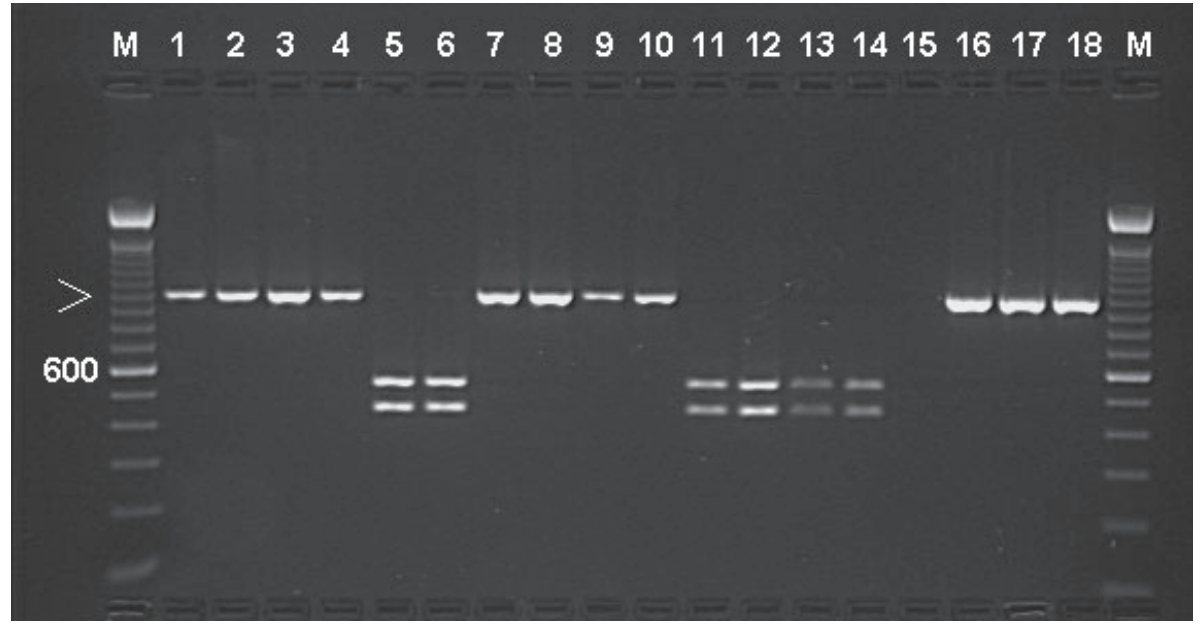

(b)

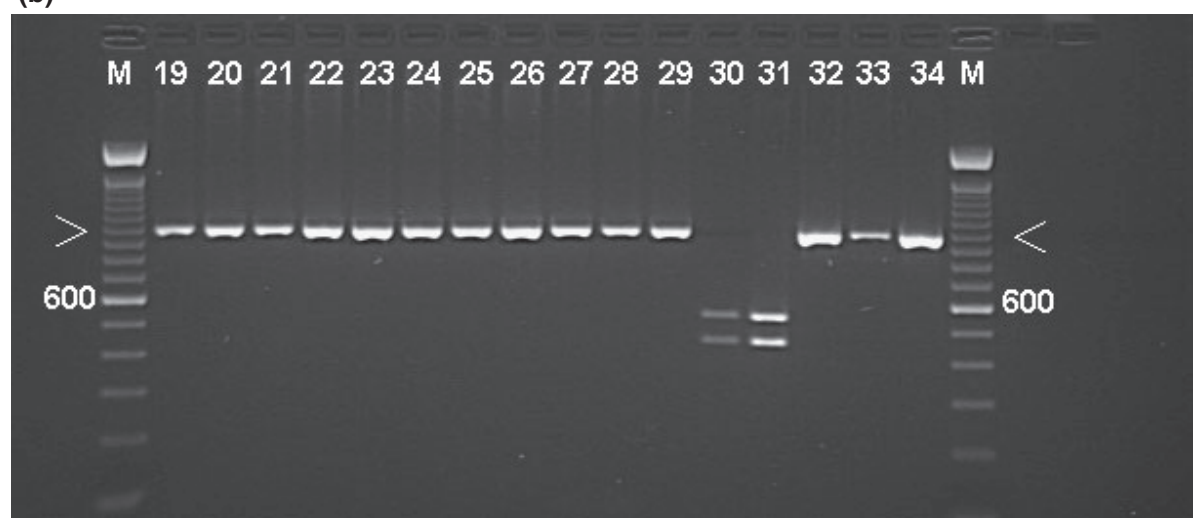

Fig. 4. (a,b) Restriction fragment-length polymorphism patterns for the 972-bp amplicon of the cytochrome C oxidase subunit 1 gene for 24 samples of DNA from isolates of Phytophthora ramorum from Europe (lanes 19, 20, 21, 22, and 23), the United States (lanes 1-9, 24-28) and Canada (lanes 10, 11, 12, 13, 14), Aval digests from one isolate each of P. foliorum (lane 29), P. lateralis (lane 30) and P. hibernalis (lane 31). Lanes 16, 17 and 18 represent undigested products from PFC0-5041, PFC-5091 and CPH-16391, respectively. Lanes 32, 33 and 34 represent undigested products from PFC-5040, PFC-5069 and PFC-5071, respectively. Lane 15 is empty. A 100-bp marker is used as size reference. The arrow denotes the size of undigested product, $972 \mathrm{bp}$; ' 600 ' denotes the size of the 600-bp size marker. Details on isolates are listed in Table 1.

and occasionally in North American nurseries (GARbelotto et al. 2005; Bilodeau et al. 2007; Grunwald et al. 2008). The North American lineages (NA1 and NA2, all A2 mating type) have not been found in Europe at present.

Molecular detection methods allow for the processing of larger numbers of samples from nursery and field surveys and are less time-consuming than cultural methods. The enzymelinked immunosorbent assay (ELISA) is commonly used to screen for Phytophthora species, and then a PCR test for P. ramorum is performed. Specific primers have been 


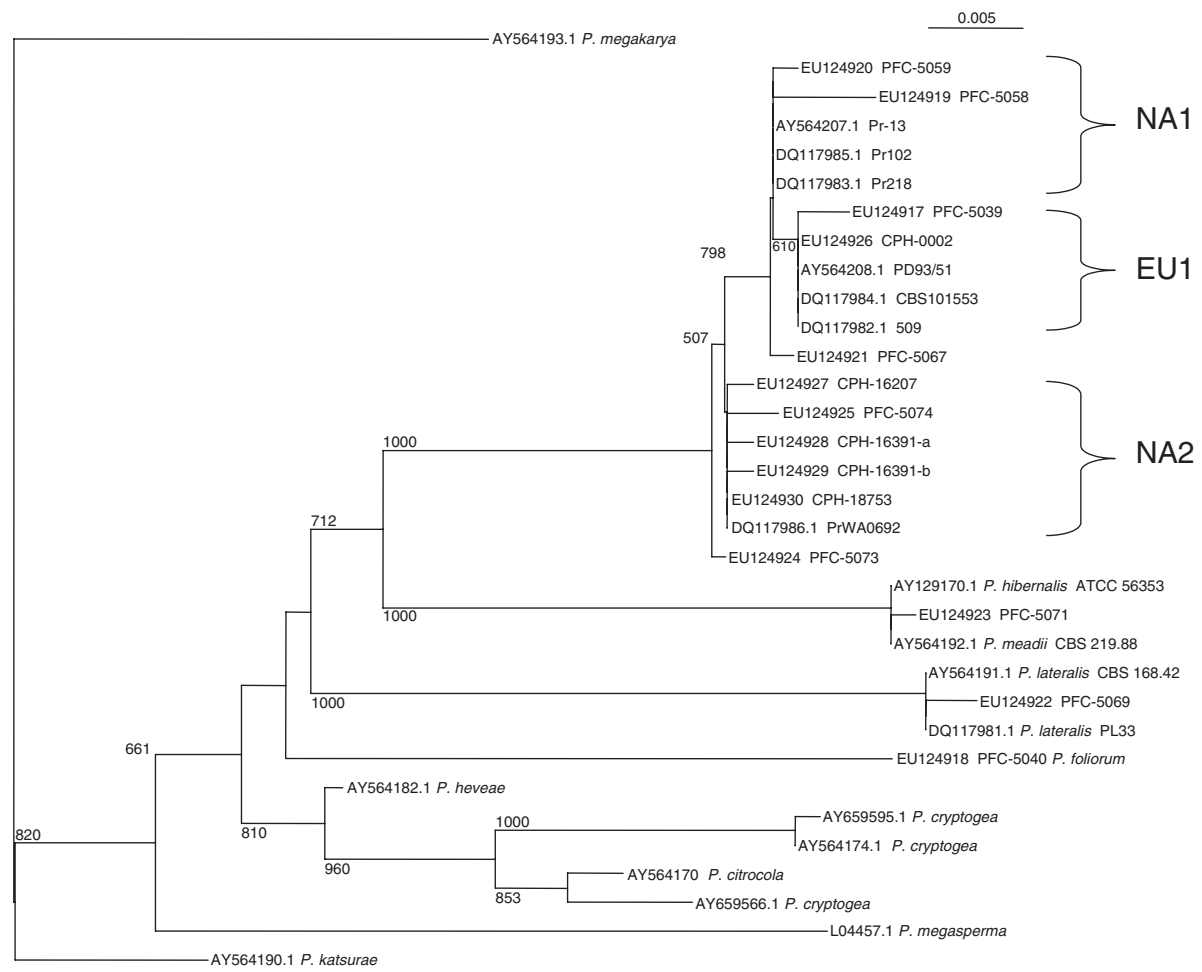

Fig. 5. Neighbour Joining phylogenetic tree based on partial cytochrome $\mathrm{C}$ oxidase subunit 1 gene sequences. Phytophthora ramorum genotypes are grouped into three distinct clades. From this study, representatives of the NA1 clade include PFC-5058 and PFC-5059. Representatives of the EU1 clade include PFC-5039, CPH-0002, and PFC-5067. Within the NA2, isolates included CPH-16207, PFC5074, CPH-16391 (two sequences), CPH-18753, and PFC-5073. Various Phytophthora ramorum accessions (isolate notation in parenthesis) as well as other Phytophthora species are included. PFC5071 grouped with P.hibernalis (accession AY129170.1) and Phytophthora meadii (accession AY564192.1). PFC-5069 grouped with two accessions of Phytophthora lateralis, AY564191.1 and DQ117981.1. Isolate PFC-5040, Phytophthora foliorum, grouped on its own. Bootstrap values are shown at tree branches (of 1000).

developed that will detect $P$. ramorum in plant material collected from the field, as well as other species that occur in the same ecological niche (MARTIN et al. 2004). Real-time PCR methods detect very small amounts of DNA from field samples, are rapid and can differentiate between isolates based on sequence because melting temperatures will differ for similarly sized products that have slight differences in sequence (BELBAHRI et al. 2007; BILOdeAu et al. 2007). Simpler methods such as PCR-RFLP and nested PCR can be performed in most laboratories and do not require specialized equipment.

Most molecular tests currently available for detecting $P$. ramorum distinguish between Phytophthora species but not clonal lineages (Martin et al. 2004; Osterbauer et al. 2004; Blomquist et al. 2005; Bilodeau et al. 2007). In tests that use the ITS region, crossreaction with other closely related species such as $P$. hibernalis, $P$. foliorum or $P$. lateralis can occur. We had access only to one isolate each of $P$. hibernalis and $P$. foliorum, but sequence data are provided for additional isolates of $P$. lateralis and $P$. hibernalis that agrees with our results. The only isolate of $P$. foliorum that has been sequenced in the Cox 1 region was done in this study, and additional data about this species would be informative. 
Bilodeau et al. (2008) found SNPs in $\beta$-tubulin and CBEL genes that distinguish between EU1 and NA populations of $P$. ramorum, but do not differentiate between NA1 and NA2, similar to the results obtained by KROon et al. (2004) using RFLP of the Cox1 gene. Microsatellite markers can provide a more precise identification of $P$. ramorum populations (Ivors et al. 2006; Prospero et al. 2007).

The molecular tests presented here involving the Cox1 region are suitable for differentiating between the three lineages of $P$. ramorum; however, $P$. foliorum cannot be separated from the NA1 group using this method. Visual examination of a culture will distinguish between the two species, because $P$. ramorum forms chlamydospores and $P$. foliorum forms oospores. It is possible to identify which lineage an isolate of $P$. ramorum belongs to using PCR-RFLP of the Cox1 gene, first using ApoI to separate $P$. ramorum from other species and EU1 from North American populations, and AvaI to distinguish between NA1 and NA2 genotypes. These markers could be adapted for use in other assays, such as real-time PCR.

\section{Acknowledgements}

The authors wish to thank the Natural Sciences and Engineering Research Council of Canada (NSERC), Canadian Forest Service (CFS) and the Canadian Food Inspection Agency (CFIA) for financial support. Partial funding to NJG for this study was also provided by the USDA ARS CRIS project 5358-22000-034-00.

\section{References}

Belbahri, L.; Calmin, G.; Wagner, S.; Moralejo, E.; Woodward, S.; Lefort, F., 2007: Specific hybridization real-time PCR probes for Phytophthora ramorum detection and diagnosis. For. Path. 37, 403-408.

Bilodeau, G. J.; Lévesque, C. A.; De Cock, A. W. A. M.; Duchaine, C.; Brière, S.; Uribe, P.; Martin, F. N.; Hamelin, R. C., 2007: Molecular detection of Phytophthora ramorum by real timePCR using TaqMan, SYBR green, and molecular beacons. Phytopathology 97, 632-642.

Bilodeau, G. J.; Lévesque, C. A.; De Cock, A. W. A. M.; Brière, S.; Hamelin, R. C., 2008: Differentiation of European and North American genotypes of Phytophthora ramorum by realtime polymerase chain reaction primer extension. Can. J. Plant Pathol. 29, 408-420.

Blair, J.E.; Coffey, M.D.; Park, S.-Y; Geiser, D.M.; Kang, S., 2008. A multi-locus phylogeny for Phytophthora utilizing markers derived from complete genome sequences. Fungal Genet. Biol. 45, 266-277.

Blomquist, C.; Irving, T.; Osterbauer, N.; Reeser, P. 2005: Phytophthora hibernalis: A new pathogen on Rhododendron and evidence of cross amplification with two PCR detection assays for Phytophthora ramorum. Plant Health Progr. (online), doi: 10.1094/PHP-2005-0728-01-HN.

Brasier, C. M.; Kirk, S.; Rose, J. 2005: Adaptive differences between Phytophthora ramorum isolates from Europe and North America: evidence for separate subspecies? In: Proceedings of the Sudden Oak Death Second Science Symposium: The State of our Knowledge. Ed. by Frankel, S. J., Shea, P. J. and Haverty, M. I. 18-21 January 2005; Monterey, CA: Pacific Southwest Research Station, Forest Service, U.S. Department of Agriculture. General Technical Report PSW-GTR-196. pp 101105.

Brasier, C. M.; Kirk, S.; Rose, J., 2006: Differences in phenotypic stability and adaptive variation between the main European and American lineages of Phytophthora ramorum. In: Progress in Research on Phytophthora Diseases of Forest Trees. 3rd Int. IUFRO Work. Party Meet. , Friesing, Germany, Ed. by Brasier, C. M.; Jung, T.; Oswald, W. Farnham, Surrey, UK: Forest Research Alice Holt Lodge, pp. 166-173.

Donahoo, R.; Blomquist, C. L.; Thomas, S. L.; Moulton, J. K.; Cooke, D. E. L.; Lamour, K. H., 2006: Phytophthora foliorum sp. nov., a new species causing leaf blight of azalea. Mycol. Res. 110, 1309-1322.

EPPO, 2006: Phytophthora ramorum (available at: http://www.eppo.org/QUARANTINE/Alert_ List/fungi/PHYTRA.htm).

Garbelotto, M.; Ivors, K.; Huberli, D.; Bonants, P.; Wagner, A., 2005: Potential for sexual reproduction of Phytophthora ramorum in Washington State nurseries. Page 129. In: Proceedings 
of the Sudden Oak Death second science symposium: the state of our knowledge. Ed. by FrankEL, S. J.; Shea, P. J.; Haverty, M. I. technical coordinators. Monterey, CA: USDA For. Serv. Gen Tech. Rep. PSW-GTR-196: pp. 79-83.

Goodwin, S. B.; Sujkowski, L. S.; Fry, W. E., 1995: Rapid evolution of pathogenicity within clonal lineages of the potato late blight disease fungus. Phytopathology 85, 669-676.

Grunwald, N. J.; Goss, E. M.; Larsen, M. M.; Press, C. M.; McDonald, V. T.; Blomquist, C. L.; Thomas, S. L., 2008: First report of the European lineage of Phytophthora ramorum on Viburnum and Osmanthus spp. in a California nursery. Plant Dis. 92, 314.

Gu, Y. H.; Ko, W. S., 2005: Evidence for mitochondrial gene control of mating types in Phytophthora. Can. J. Microbiol. 51, 934-940.

Hansen, E. M.; Reeser, P. W.; Sutton, W.; Winton, L. M., 2003: First report of A1 mating type of Phytophthora ramorum in North America. Plant Dis. 87, 1267.

Ho, H. H.; Jong, S. C., 1993: Phytophthora hibernalis and P. syringae. Mycotaxon 47, 439-460.

Ivors, K.; Garbelotto, M.; Vries, I. D. E.; Ruyter-Spira, C.; Hekkert, B. T. E.; Rosenzweig, N.; Bonants, P., 2006: Microsatellite markers identify three lineages of Phytophthora ramorum in US nurseries, yet single lineages in US forest and European nursery populations. Mol. Ecol. 15, 14931505.

Judelson, H. S., 1996: Genetic and physical variability at the mating type locus of the Oomycete, Phytophthora infestans. Genetics 144, 1005-1013.

Judelson, H. S.; YANG, G. E., 1998: Recombination pathways in Phytophthora infestans: polyploidy resulting from aberrant sexual development and zoospore-mediated heterokaryosis. Mycol. Res. $102,1245-1253$.

Kroon, L. P. N. M.; Verstappen, E. C. P.; Kox, L. F. F.; Flier, W. G.; Bonants, P. J. M., 2004: A rapid diagnostic test to distinguish between American and European populations of Phytophthora ramorum. Phytopathology 94, 613-620.

Martin, F. N., 2008: Mitochondrial haplotype determination in the oomycete plant pathogen Phytophthora ramorum. Curr. Genet. 54, 23-34.

Martin, F. N.; Tooley, P. W.; Blomeuist, C., 2004: Molecular detection of Phytophthora ramorum, P. nemorosa and P. pseudosyringae associated with sudden oak death in California. Phytopathology 94, 621-631.

Mascheretti, S.; Croucher, P. J. P.; Vettraino, A.; Prospero, S.; Garbelotto, M., 2008 : Reconstruction of the sudden oak death epidemic in California through microsatellite analysis of the pathogen Phytophthora ramorum. Mol. Ecol. 17, 2755-2768.

Osterbauer, N.; Trippe, A., 2005: Comparing diagnostic protocols for Phytophthora ramorum in rhododendron leaves. Plant Health Progr. (online), doi: 10.1094/PHP-2005-0314-01-HN.

Osterbauer, N. K.; Griesbach, J. A.; Hedburg, J., 2004. Surveying for and eradicating Phytophthora ramorum in agricultural commodities. Plant Health Progr. (online), doi: 10.1094/PHP-2004-030902-RS.

Perrière, G.; Gouy, M., 1996: WWW-Query: An on-line retrieval system for biological sequence banks. Biochimie 78, 364-369.

Pritham, E. J.; Putliwala, T.; Feschotte, C., 2007: Mavericks, a novel class of giant transposable elements widespread in eukaryotes and related to DNA viruses. Gene 390, 3-17.

Prospero, S.; Hansen, E. M.; Grünwald, N. J.; Winton, M., 2007: Population dynamics of the sudden oak death pathogen Phytophthora ramorum in Oregon from 2001 to 2004. Mol. Ecol. 16, 2958-2973.

Thompson, J. D.; Gibson, T. J.; Plewniak, F.; Jeanmougin, F.; Higgins, D. G., 1997: The ClustalX windows interface: flexible strategies for multiple sequence alignment aided by quality analysis tools. Nucleic Acids Res. 24, 4876-4882.

Tooley, P. W.; Hewings, A. D.; Falkenstein, K. F., 1989: Detection of double-stranded RNA in Phytophthora infestans. Phytopathology 79, 470-474.

Tyler, B. M.; Tripathy, S.; Zhang, X.; Dehal, P.; Jiang, R. H. Y.; Aerts, A.; Arredondo, F. D.; Baxter, L.; Bensasson, D.; Beynon, J. L.; Chapman, J.; Damasceno, C. M. B.; Dorrance, A. E.; Dou, D.; Dickerman, A. W.; Dubchak, I. L.; Garbelotto, M.; Gijzen, M.; Gordon, S. G.; Govers, F.; Grünwald, N. J.; Huang, W.; Ivors, K. L.; Jones, R. W.; Kamoun, S.; Krampis, K.; Lamour, K. H.; Le, M.; McDonald, W. H.; Medina, M.; Meijer, H. J. G.; Nordberg, E. K.; Maclean, D. J.; Ospina-Giraldo, M. D.; Morris, P. F.; Phuntumart, V.; Putnam, N. H.; Rash, S.; Rose, J. K. C.; Sakihama, Y.; Salamov, A. A.; Savidor, A.; Scheuring, C. F.; Smith, B. M.; Sobral, B. W. S.; Terry, A.; Torto-Alalibo, T. A.; Win, J.; Xu, Z.; Zhang, H.; Grigoriev, I. V.; Rokhsar, D. S.; Boore, J. L., 2006: Phytophthora genome sequences uncover evolutionary origins and mechanisms of pathogenesis. Science 313, 1261-1266. 
USDA-APHIS, 2007: APHIS List of Hosts and Plants Associated with Phytophthora ramorum (available at: http://www.aphis.usda.gov/plant_health/plant_pest_info/pram/downloads/pdf_files/ usdaprlist.pdf).

Werres, S.; De Merlier, D., 2003: First detection of Phytophthora ramorum mating type A2 in Europe. Plant Dis. 87, 1266.

Werres, S.; Marwitz, R.; Man in ‘t Veld, W. A.; De Cock, A. W.; Bonants, P. J. M.; De Weerdt, M.; Themann, K.; Ilieva, E.; BaAyen, R. P., 2001: Phytophthora ramorum sp. nov: a new pathogen on Rhododendron and Viburnum. Mycol. Res. 105, 1155-1165.

Yakabe, L. C.; Blomquist, S.; Thomas, J.; MacDonald, J. D., 2007: Identification and frequency of Phytophthora species causing foliar diseases in California ornamental nurseries. Phytopathology 97, S126. 